\title{
TRICHOMONAS VAGINALIS INFESTATION IN WOMEN
}

I have found that $T$. vaginalis was present in forty-two per cent of the gonorrhoeal cases and I believe that this figure would have been higher if I had continued the search. Therefore it is well to bear in mind that a certain number of cases treated for trichomonas infestation will reveal on completion of treatment, a gonococcal infection which had previously been sought for without success.

\section{Mode of infection}

This has been attributed to bath water, towels and clothing of infected persons, but 1 think this mode of spread must be rare, as the parasite requires a certain degree of moisture and heat to keep it alive. In civilian life I was struck by the fact that women of low economic standards were more frequently affected and I thought that vitamin deficiency might play a part, but this cannot be said of women in the Armed Services, who today are having a mixed and well balanced diet which is far superior to that of a large percentage of the population in pre-war days.

One author maintains that $T$. vaginalis appears in the vagina merely as a secondary invader, in conditions caused by other organisms, e.g. B. coli and the gonococcus.

Hibbert and Falls (1938) thought that an independent causative agent other than $T$. vaginalis might produce the clinical syndrome and that a symbiotic relationship between the trichomonas and a streptococcus may be the causative factor. They also suggested the failure of normal carriers of the parasite to show clinical signs may be due to the immunity established against these two factors.

\section{Conclusions}

(1) I would suggest that a large number of women are carriers of $T$. vaginalis which, when the vaginal $p \mathrm{H}$ is normal, are of no significance.

(2) In this group of women, $T$. vaginalis becomes pathogenic, only when the $p \mathrm{H}$ of the vagina has been primarily altered by other invading organisms, for example, gonococci, $B$. coli, streptococci and others. Trauma, uncleanliness, the presence of cervical erosions and general debility after an illness are adjuvant factors.

(3) An external invasion of $T$. vaginalis, the source being difficult to state, may take place in any unhealthy vagina with an abnormal $p \mathrm{H}$.

(4) The condition which is widespread amongst the female community, both in civilian and service life and which is of medical and economic importance (for many hours are spent in hospitals and treatment centrès) is well worthy of further investigation.

\section{REFERENCES}

Brady, L., and Reid, R. D. (1942) Ann. Surg., 115, 840.

Cornell, E. L., Goodwin, L. J., and Matthies, M. M. (1931) Amer. J. Obstet. Gynec., 22, 360.

Dobell, C. (1934) Parasitology, 26, 531.

Hibbert, G. F., and Falls, F. H. (1938) Amer. J. Obstet. Gynec., 36, 219.

Karnaky, K. J. (1940) Amer. J. Surg., N.S., 48, 216.

Lewis, B., and Carroll, G. (1928) J. Urol., 19, 337.

Liston, W. G. (1940) Brit. J. vener. Dis., 16, 113.

- and Lees, R. (1940) Brit. J. vener. Dis., 16, 34.

- and Liston, W. A. (1939) J. Obstet. Gynaec., 46, 474.

Nitschke, P. H. (1936) J. Amer. med. Ass., 107, 12.

Rosenthal, D. B. (1931) Med. J. Aust., 1, 782.

Wenyon, C. M. (1926) Protozoology. A Manual for Medical Men, Veterinarians and Zoologists, London.

\section{Ante-natal serological tests for syphilis}

The desire in many medical circles for the application of routine tests for syphilis to all pregnant women has recently received the approbation of the executive committee of the National Association of Maternity and Child Welfare Centres.

The opinion of the executive committee of this Association was expressed in the resolution adopted at its meeting on 24th May, which considered that the physical and social disadvantages to a child with congenital syphilis are such that everything practicable should be done to diagnose the condition at the earliest possible time, including the routine application of syphilis blood tests to the mother during pregnancy in order that effective treatment may be given. A resolution was also adopted that the Ministry of Health should give practical effect to this by propaganda and by stimulating welfare authorities, voluntary hospitals and clinics. 